\title{
RESPOSTAS BIOMÉTRICAS DE PLANTAS DE TRIGO SUBMETIDAS A DIFERENTES DOSES DE NITROGÊNIO EM COBERTURA
}

\author{
${ }^{1}$ Martios Ecco, ${ }^{2}$ Rodrigo Felipe Perin, ${ }^{2}$ Raul Pereira Duarte, ${ }^{1}$ André Prechlak Barbosa, ${ }^{2}$ Angelo Marcio \\ Gabriel \\ ${ }^{1}$ Professor Dr. do curso de Agronomia da Pontifícia Universidade Católica do Paraná, campus Toledo, Avenida da União, 500, \\ 85902-532, Toledo, PR. E-mail: ecco.martios@pucpr.br; andre.prechlak@pucpr.br ²Engenheiro agrônomo pela Pontifícia \\ Universidade Católica do Paraná, campus Toledo, Avenida da União, 500, 85902-532, Toledo, PR. E-mail: \\ rodrigoperin2009@hotmail.com; duarte.agro@hotmail.com; angelomgabriel@hotmail.com
}

RESUMO: A utilização de cultivares de trigo de alto potencial e a adubação nitrogenada são essenciais para obtenção de altas produtividades. Os cereais de inverno cultivados no sul do Brasil, geralmente apresentam resposta significativas à aplicação de N. Isso decorre do suprimento insuficiente pelo solo para atender a demanda dessas plantas. Objetivando avaliar os efeitos de doses de nitrogênio, sobre os componentes de produção e a produtividade de trigo, aplicadas em cobertura, sob semeadura direta, foi conduzido este experimento no município de Ouro Verde do Oeste - PR, utilizando um delineamento de blocos casualizados, com quatro repetições. Os tratamentos consistiram da em cinco doses de $\mathrm{N}, 0,30$, 60,90 e $120 \mathrm{~kg} \mathrm{ha}^{-1}$, utilizando como fonte de $\mathrm{N}$ a ureia em cobertura. A aplicação do nitrogênio influenciou positivamente o número de perfilhos e o comprimento da espiga das plantas de trigo até doses de aproximadamente $66 \mathrm{~kg} \mathrm{ha}^{-1}$ de $\mathrm{N}$, entretanto, estas variáveis não influenciaram a produtividade de grãos. Doses acima de $30 \mathrm{~kg} \mathrm{ha}^{-1}$ de $\mathrm{N}$ em cobertura influenciaram negativamente a massa de mil grãos, e pode ter ocasionado o baixo $\mathrm{PH}$ observado, uma vez que o número de perfilhos que foi acrescido gerou maior divisão dos fotoassimilados pelas plantas.

Palavras-chave: Adubação. Cereais de inverno. Produtividade. Triticum aestivum

\section{BIOMETRIC RESPONSES OF WHEAT PLANTS SUBMITTED TO DIFFERENT DOES OF NITROGEN}

ABSTRACT: The use of high potential wheat cultivars and nitrogen fertilization are essential to obtain high yields. Winter cereals grown in southern Brazil generally present a significant response to the application of $N$. This is due to insufficient soil supply to meet the demand of these plants. The objective of this study was to evaluate the effects of nitrogen doses, on the production components and the yield of wheat applied under cover, under no-tillage, in the city of Ouro Verde do Oeste - PR, using a randomized complete block design four replicates. The treatments consisted of five doses of $\mathrm{N}, 0,30,60,90$ and $120 \mathrm{~kg} \mathrm{ha}^{-1}$, using as a source of $N$ the urea under cover. Nitrogen application positively influenced the number of tillers and ear length of wheat plants up to approximately $66 \mathrm{~kg} \mathrm{ha}^{-1}$ of $\mathrm{N}$, however, these variables 
did not influence grain yield. Doses above $30 \mathrm{~kg} \mathrm{ha}^{-1}$ of $N$ on cover negatively influence the mass of a thousand grains, and may have caused the low $\mathrm{PH}$ observed, since the number of tillers that was added generates a greater division of photo-assimilates by the plants.

Keywords: Fertilizing. Winter cereals. Productivity. Triticum aestivum

\section{INTRODUÇÃO}

A utilização de cultivares de alto potencial produtivo para atender as mais elevadas exigências em termos de qualidade e produtividade devem estar associadas a um conjunto de fatores dentre os quais podemos destacar o uso eficiente dos fertilizantes, fator que implica diretamente nos custos de produção para o produtor. Desta forma, a adubação nitrogenada é uma das mais importantes, afetando crescimento e o desenvolvimento das plantas, influenciando o seu potencial produtivo e qualitativo, requerendo cuidados no manuseio na época de aplicação e doses.

Pequenas doses de nitrogênio $(\mathrm{N})$ podem limitar a produtividade pela falta de formação de reservas nos perfilhos e, altas doses deste elemento no final do perfilhamento, pode gerar a necessidade de aplicação de redutor de crescimento durante a elongação do colmo e, se não aplicado pode resultar em acamamento de plantas, dificultando assim a colheita e resultando em queda de produtividade e qualidade de grãos.

$\mathrm{O} \mathrm{N}$ aplicado pode apresentar algumas particularidades em função do tipo e condições de solo, cobertura existente no solo, podendo ainda sua disponibilidade ser afetada por processos de volatilização, imobilização microbiana e lixiviação de nitrato acarretando em prejuízos econômicos e ambientais para o produtor (REIS et al., 2010).

Por ser um elemento essencial para as plantas sendo um dos mais absorvidos, o $\mathrm{N}$ participa de uma série de rotas metabólicas-chaves em sua bioquímica, podendo ser absorvido de duas formas distintas, tanto em forma de ânion $\mathrm{NO}_{3}{ }^{-}$como na de cátion $\mathrm{NH}_{4}{ }^{+}$, também chamadas de $\mathrm{N}$ mineral. Nas plantas 0 $\mathrm{N}$ desempenha papel fundamental, participando na constituição de proteínas, ácidos 
nucléicos além de importante constituinte de biomoléculas tais como ATP, NADH, NADPH, clorofila, membranas e diversos hormônios vegetais (FERNANDES, 2006).

Pela sua importância no processo de desenvolvimento das plantas a correta época de aplicação é fundamental para incrementos de produtividade, devendo-se tomar cuidado com aplicações muito precoces ou muito tardias pelo pouco aproveitamento, e até mesmo sua interação com o meio (SILVA et al., 2005). Sendo assim aplicar o $\mathrm{N}$ no momento certo pode aumentar sua eficiência de uso pelo trigo, incrementando o número de grãos por espiga e o número de espigas por área.

Estudos avaliando a adubação nitrogenada são fundamentais para atualizar as recomendações técnicas e disponibilizar tecnologias que proporcionem produções economicamente satisfatórias. No Estado do Paraná a dose de $\mathrm{N}$ é recomendada em função da cultura antecessora, sendo Soja, em semeadura (25-50 $\mathrm{kg} \mathrm{ha}^{-1}$ de N), e em cobertura (30-90 kg ha-1 de N), (CBPTT, 2013). Zagonel et al. (2002), Trindade et al. (2006) e Teixeira Filho et al. (2010) avaliaram fontes e épocas de aplicação de $\mathrm{N}$ em trigo irrigado em plantio direto e observaram respostas positivas, para o aumento da produtividade, utilizando doses de $\mathrm{N}$ de até $121,5 \mathrm{~kg}$ ha $^{-1}$.

Desta forma, é importante ressaltar que altas produtividades para a cultura requerem boa fertilidade do solo, diante deste fator, a deficiência de $\mathrm{N}$ pode comprometer os processos de crescimento, desenvolvimento das plantas, acarretando redução das variáveis biométricas como o número de perfilhos, diâmetro dos mesmos, massa de grãos e $\mathrm{PH}$, responsáveis pela produtividade.

Todavia, os estudos sobre a resposta dos componentes de produção e produtividade do trigo à adubação nitrogenada são insuficientes, e devem ser relizados em condições específicas de ambiente. Sendo assim, o objetivo deste trabalho foi avaliar os efeitos de doses de nitrogênio, sobre os componentes de produção e a produtividade de trigo, aplicados em cobertura, sob semeadura direta.

\section{MATERIAL E MÉTODOS}

O experimento foi conduzido a campo em propriedade particular no município de Ouro Verde do Oeste - Paraná, coordenadas geográficas 2448' 54.37" S e $53^{\circ} 54^{\prime} 1,27^{\prime \prime}$ O. A altitude média da área experimental é $520 \mathrm{~m}$ e o clima é 
classificado como sendo subtropical úmido ( $\mathrm{Cfa}$ ), com temperatura média no mês mais frio inferior a $18^{\circ} \mathrm{C}$ (mesotérmico) e temperatura média no mês mais quente acima de $22^{\circ} \mathrm{C}$, com verões quentes, geadas pouco frequentes e tendência de concentração das chuvas nos meses de verão, contudo sem estação seca definida (IAPAR, 2013).

O solo da área experimental é de textura média (tipo 2) de média fertilidade, classificado como Latossolo Vermelho distroférrico (SANTOS et al., 2018), sendo a cultura antecessora a implantação do experimento o milho. Os atributos químicos do solo determinados antes da instalação do experimento utilizando um trado holandês, segundo metodologia proposta por Raij et al. (2001) apresentaram os seguintes resultados na camada de 0 a $20 \mathrm{~cm}$ : pH em CaCl 2 0,01 $\mathrm{mol} \mathrm{L}^{-1}: 5,06 ; \mathrm{P}: 19,70 \mathrm{mg}$

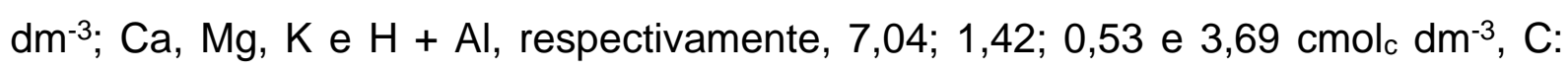
2,26 $\mathrm{g} \mathrm{dm}^{-3}$; T: 12,68; V\%: 70,90.

$O$ delineamento experimental foi o de blocos ao acaso, sendo os tratamentos compostos por cinco doses de $\mathrm{N}$ aplicadas em cobertura $\left(0,30,60,90,120 \mathrm{~kg} \mathrm{ha}^{-1}\right)$, com quatro repetições, onde que as doses de $\mathrm{N}$ foram baseadas na exigência nutricional da cultura do trigo. Cada unidade experimental teve dimensão de 3,57 x 4 $\mathrm{m}$, composta por 21 linhas de $0,17 \mathrm{~m}$, totalizando $14,28 \mathrm{~m}^{2}$ e $8,67 \mathrm{~m}^{2}$ de área útil. A semeadura foi realizada com auxílio de uma semeadora/adubadora de fluxo contínuo sob sistema de semeadura direta (20 anos de implantação do sistema) da marca Semeato, modelo SPD21.

A cultivar de trigo utilizada foi a CD 150 de ciclo precoce, que apresenta de 110 a 120 dias até a maturação. É um material moderadamente resistente a ferrugem da folha, suscetível a Giberela zeae, com textura dos grãos dura, resistente ao acamamento por se tratar de uma planta de porte baixo $(68 \mathrm{~cm})$ de altura e qualidade industrial classificado como melhorador, recomendado para ser semeado em solos de fertilidade média a alta (COODETEC, 2014).

Quanto ao manejo da área foi realizada a dessecação utilizando o herbicida glyphosate (1500 $\mathrm{g} \mathrm{ha}^{-1}$ do i.a.), além do tratamento de sementes com carboxin + thiram $\left(60+60\right.$ g i.a. $100 \mathrm{~kg}^{-1}$ de sementes). A semeadura foi realizada no dia 07 de maio de 2014, com uma profundidade média de $3 \mathrm{~cm}$ utilizando-se 330 sementes viáveis por $\mathrm{m}^{2}$, com 55 sementes viáveis por metro. 
A adubação com nitrogênio, fósforo e potássio (NPK), na semeadura, foi realizada conforme os resultados da análise química do solo, seguindo-se as indicações técnicas da Comissão Brasileira de Pesquisa de Trigo e Triticale para o Estado do Paraná (FRANCO; EVANGELISTA, 2018). Na adubação de semeadura, foram distribuídos, no sulco de semeadura, $310 \mathrm{~kg} \mathrm{ha}^{-1}$ da fórmula 10-15-15, correspondendo a $31 \mathrm{~kg} \mathrm{ha}^{-1}$ de N, $46 \mathrm{~kg} \mathrm{ha}^{-1}$ de $\mathrm{P}_{2} \mathrm{O}_{5}$ e $46 \mathrm{~kg} \mathrm{ha}^{-1}$ de $\mathrm{K}_{2} \mathrm{O}$.

Quanto a adubação nitrogenada de cobertura foi aplicada na data 13 de junho de 2014, nas entrelinhas das parcelas, de forma manual, sem incorporação ao solo, 35 dias após a emergência das plantas, quando a planta se encontrava no período de início de perfilhamento (E2), conforme escala de Feekes modificado por Large (1954), sendo a fonte utilizada ureia ( $45 \%$ de $\mathrm{N})$.

O manejo de plantas daninhas foi efetuado com a aplicação do herbicida metsulfuron methyl (3,0 $\mathrm{g}$ ha $^{-1}$ do i.a.) em pós-emergência no estádio vegetativo E2, e para o controle de pragas, Lambda Cyhalotrin e Tiametoxam (150 mL ha-1 do i.a) e doenças foram realizadas duas aplicações do fungicida, Ciproconazol, Picoxistrobina (300 $\mathrm{mL} \mathrm{ha}^{-1}$ do i.a).

As aplicações foram realizadas de forma mecânica, com a utilização de pulverizador hidráulico de $800 \mathrm{~L}^{-1}$, com $14 \mathrm{~m}$ de barra de aplicação, com pressão constante de $32 \mathrm{psi}$, com vazão de $80 \mathrm{~L} \mathrm{ha}^{-1}$, utilizando bico cônico com espaçamento de $0,5 \mathrm{~m}$ entre bicos, com velocidade constante de $6 \mathrm{~km} \mathrm{~h}^{-1}$.

Os parâmetros biométricos, avaliados na área útil de cada parcela, foram colhidas manualmente todas as plantas e submetidas a secagem a pleno sol, e posteriormente trilhadas de forma mecânica realizando-se abanação manual para a limpeza. Avaliou-se, os componentes de rendimento, altura de plantas (AP), com auxílio de uma trena graduada medindo-se ao nível do solo ao ápice das espigas, tamanho de espiga (TE), com a coleta de 20 espigas aleatoriamente dentro da área útil de cada parcela com paquímetro manual, número de espiguetas (NE), contagem manual de espiguetas por espiga, número de grãos por espiga (NGE), através de debulha manual.

Para o fator produtividade realizou-se a coleta das plantas dentro da área útil. Após a trilha mecânica os grãos foram pesados com uma balança digital e os resultados foram tabulados e ajustados em $\mathrm{kg} \mathrm{ha}^{-1}$ a $13 \%$ de umidade. Para massa 
de mil grãos realizou-se a pesagem das parcelas em balança de precisão com umidade ajustada a 13\%, conforme metodologia descrita por Brasil (2009). E por fim para peso de hectolitro $(\mathrm{PH})$, correspondente à massa de grãos ocupada em um volume de $100 \mathrm{~L}$, determinada em balança de 0,25 L, com teor de água dos grãos corrigidos para $13 \%$ (base úmida).

Os dados obtidos foram tabulados e submetidos a análise de variância $(p<0,05)$, pelo teste $F$, e as medias quantitativas comparadas pelo teste de regressão $(p<0,05)$. As análises foram executadas utilizando o programa estatístico SISVAR 5.4 - Sistema para análise de variância (FERREIRA, 2011).

\section{RESULTADOS}

$\mathrm{O}$ efeito das doses de $\mathrm{N}$ nas variáveis analisadas foi significativo $(p<0,05)$ para o número de perfilhos e tamanho de espiga, não havendo alteração para altura de plantas e número de espiguetas (Tabela 1 ).

Tabela 1 - Valores de F, coeficiente de variação (CV), Altura de Plantas (AP), Número de Perfilhos (NP), Tamanho de Espigas (TE) e Número de Espiguetas (NE) em função das diferentes doses de nitrogênio (N) em cobertura na cultura do trigo cultivado em Ouro Verde do Oeste - PR

\begin{tabular}{|c|c|c|c|c|c|}
\hline \multirow{2}{*}{ Fontes de Variação } & \multirow{2}{*}{ G.L. } & \multicolumn{4}{|c|}{ Q.M. } \\
\hline & & $\mathrm{AP}(\mathrm{cm})$ & NP & TE (cm) & NE \\
\hline Bloco (B) & 3 & $13,46^{\mathrm{NS}}$ & $0,35^{\mathrm{NS}}$ & $0,48^{\mathrm{NS}}$ & $0,52^{\mathrm{NS}}$ \\
\hline Dose (D) & 4 & $7,36^{\mathrm{NS}}$ & $2,03^{*}$ & $0,63^{*}$ & $2,67^{N S}$ \\
\hline Resíduo & 12 & 11,40 & 0,61 & 0,17 & 1,45 \\
\hline C.V. (\%) & & 5,41 & 23,14 & 5,86 & 7,32 \\
\hline Média Geral & & 62,44 & 3,38 & 6,99 & 16,43 \\
\hline
\end{tabular}

Quanto a avaliação do número de perfilhos, se observou diferenças significativas para as doses de nitrogênio aplicadas (Figura 1) onde pelo ajuste quadrático do modelo matemático da regressão, permitiu identificar que a dosagem de $66 \mathrm{~kg} \mathrm{ha}^{-1}$ de $\mathrm{N}$ proporcionou em uma média de 4,05 perfilhos por planta, sendo as doses acima destas resultando em menos perfilhos por planta. 


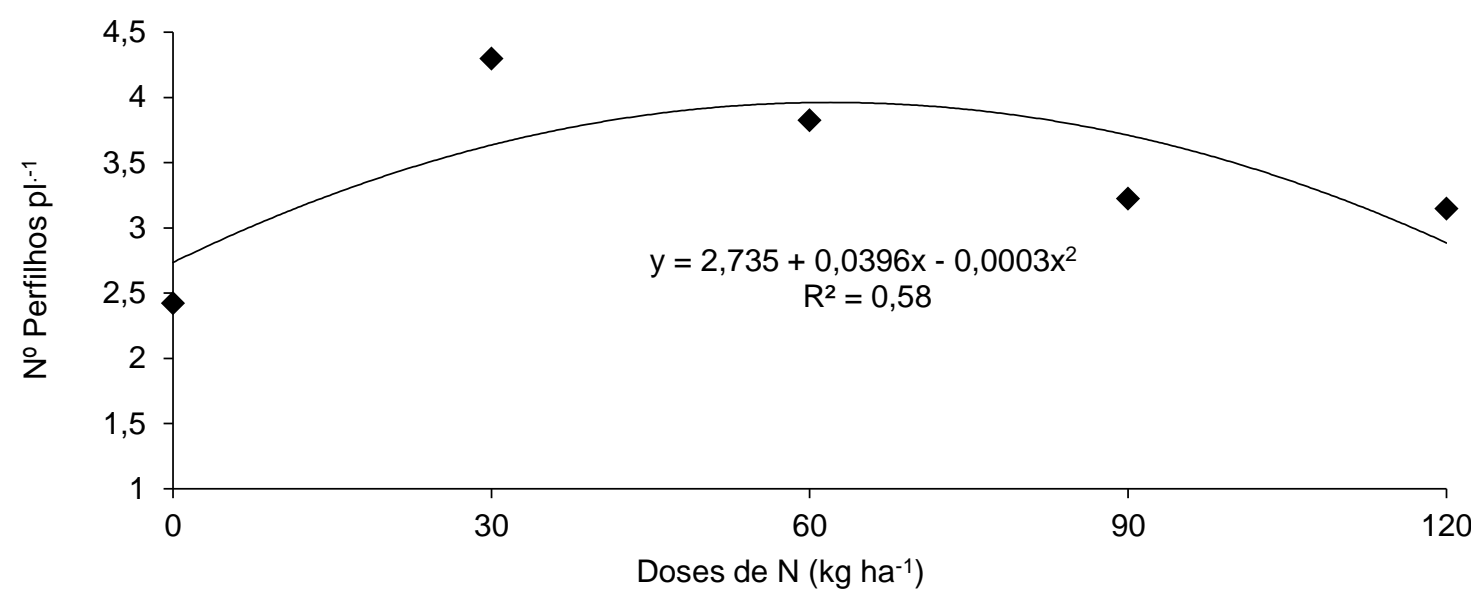

Figura 1. Número de perfilhos em função das doses de nitrogênio aplicadas em trigo cultivado em Ouro Verde do Oeste - PR.

Para a variável tamanho de espiga das plantas de trigo obteve-se resultado positivo sendo influenciada pelas doses de nitrogênio aplicadas (Figura 2), podendo observar comportamento muito similar a variável número de perfilhos, influenciando positivamente o tamanho da espiga devido possivelmente as reservas acumuladas nos perfilhos inférteis atuando como fonte e não como perfilhos dreno. Pelo ajuste da equação da regressão, a dose de $58,5 \mathrm{~kg} \mathrm{ha}^{-1}$ de $\mathrm{N}$ proporcionou em um tamanho médio de espiga de $7,18 \mathrm{~cm}$, havendo decréscimo do tamanho desta variável para doses acima desta.

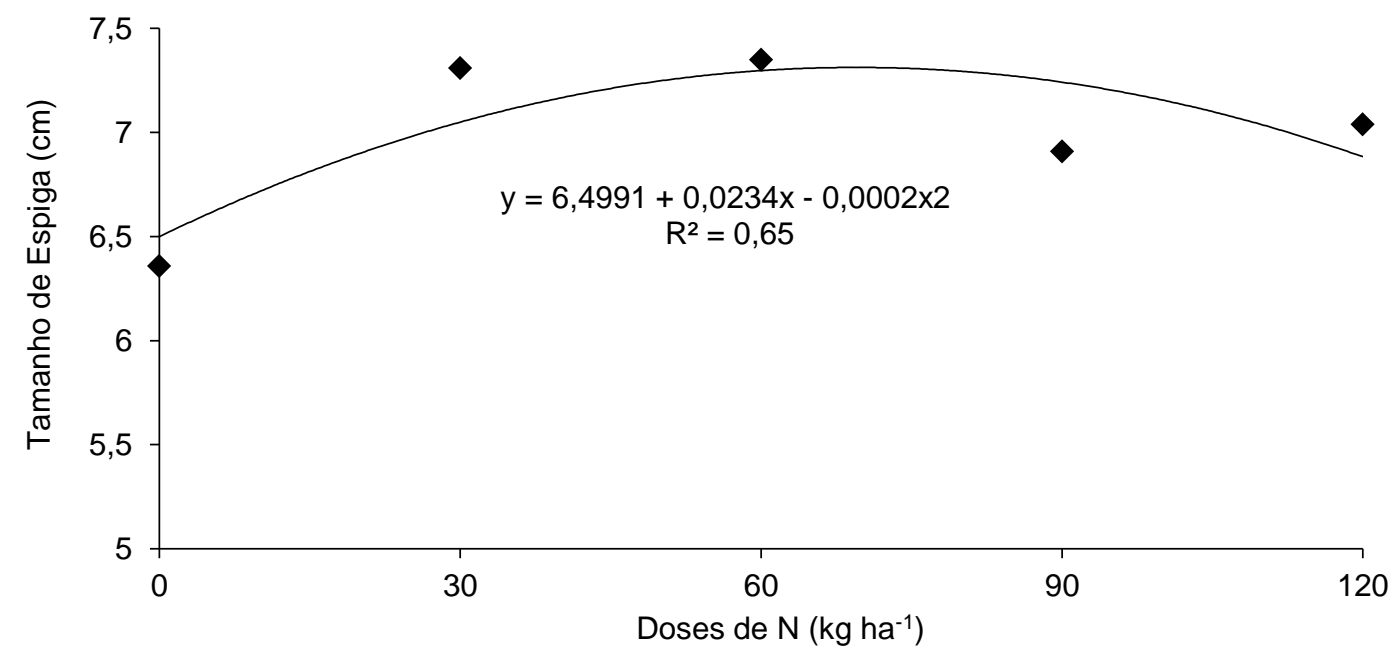

Figura 2. Tamanho de espiga em função das doses de nitrogênio aplicadas em trigo cultivado em Ouro Verde do Oeste - PR.

Em relação à avaliação número de espiguetas, não houve diferença significativa. Este fato pode estar relacionado as doses de $\mathrm{N}$ aplicadas uma vez que o mesmo promove maior vigor vegetativo, principalmente na fase de perfilhamento e 
diferenciação do meristema reprodutivo, resultando em maiores valores para estes componentes de produção, aliados a boas condições nutricionais presentes no local, além da dose fornecida. Mesmo aumentando o tamanho da espiga até determinada dosagem como na figura 2, não resultou em maior número de espiguetas, portanto, foi observado maiores espaços entre as espiguetas na ráquis da espiga, maior comprimento de entrenós da ráquis, estrutura na qual as espiguetas ficam inseridas em seus nós.

Para os parâmetros biométricos avaliados grãos por espiga, peso do hectolitro e produtividade, não obtiveram diferença significativa (Tabela 2).

Tabela 2. Valores de F, coeficiente de variação (CV), Grãos por Espiga (GE), Massa de Mil Grãos (MMG), Peso Hectolitro $(\mathrm{PH})$, e Produtividade em função das diferentes doses de nitrogênio $(\mathrm{N})$ em cobertura na cultura do

\begin{tabular}{|c|c|c|c|c|c|}
\hline \multirow{2}{*}{$\begin{array}{c}\text { Fontes de } \\
\text { Variação }\end{array}$} & \multirow{2}{*}{ G.L. } & \multicolumn{4}{|c|}{ Q.M. } \\
\hline & & GE & MMG & $\mathbf{P H}$ & Produtividade \\
\hline Bloco (B) & 3 & $15,88^{\mathrm{NS}}$ & $2,50^{\mathrm{NS}}$ & $5,78^{\mathrm{NS}}$ & $25704,81^{\mathrm{NS}}$ \\
\hline Dose (D) & 4 & $44,85^{\mathrm{NS}}$ & $29,53^{* *}$ & $5,17^{\mathrm{NS}}$ & $274309,07^{\mathrm{NS}}$ \\
\hline Resíduo & 12 & 20,73 & 1,99 & 4,24 & 97370,53 \\
\hline C.V. (\%) & & 10,54 & 4,57 & 2,73 & 13,02 \\
\hline Média Geral & & 43,21 & 30,62 & 75,45 & 2397,35 \\
\hline
\end{tabular}

G.L., Q.M., C.V., NS, ${ }^{*}$, ${ }^{*}$, respectivamente, grau de liberdade, quadrado médio do resíduo, coeficiente de variação, não significativo e significativo a 5 e $1 \%$ de probabilidade pelo teste $\mathrm{F}$.

Para a variável grãos por espiga não houve diferença significativa para os tratamentos avaliados. Para Trindade et al. (2006), os componentes de rendimento da cultura do trigo são afetados por vários fatores de origem ambiental e genética influenciando suas respostas quanto a rendimento e produtividade. Reitera-se que não houve efeito significativo dos tratamentos para o número de espiguetas, portanto, esperava-se também que não houvesse efeito para esta variável na qual estão diretamente relacionadas.

Para o parâmetro biométrico massa de mil grãos, houve diferença significativa para as doses aplicadas pelo teste $F(p<0,05)$, o que significa que a dose de nitrogênio interferiu nesse aspecto avaliado. A variável MMG apresentou comportamento inverso à medida que houve aumento da dose de $\mathrm{N}$ e apresentou 
valores maiores quanto menor a dose empregada (Figura 3), ou seja, conforme o ajuste quadrático da regressão, a dose de $93,5 \mathrm{~kg} \mathrm{ha}^{-1}$ resultou em uma massa de apenas $26,24 \mathrm{~g}$, abaixo da massa considerada normal para a cultura do trigo de $35 \mathrm{~g}$ para cada mil grãos.

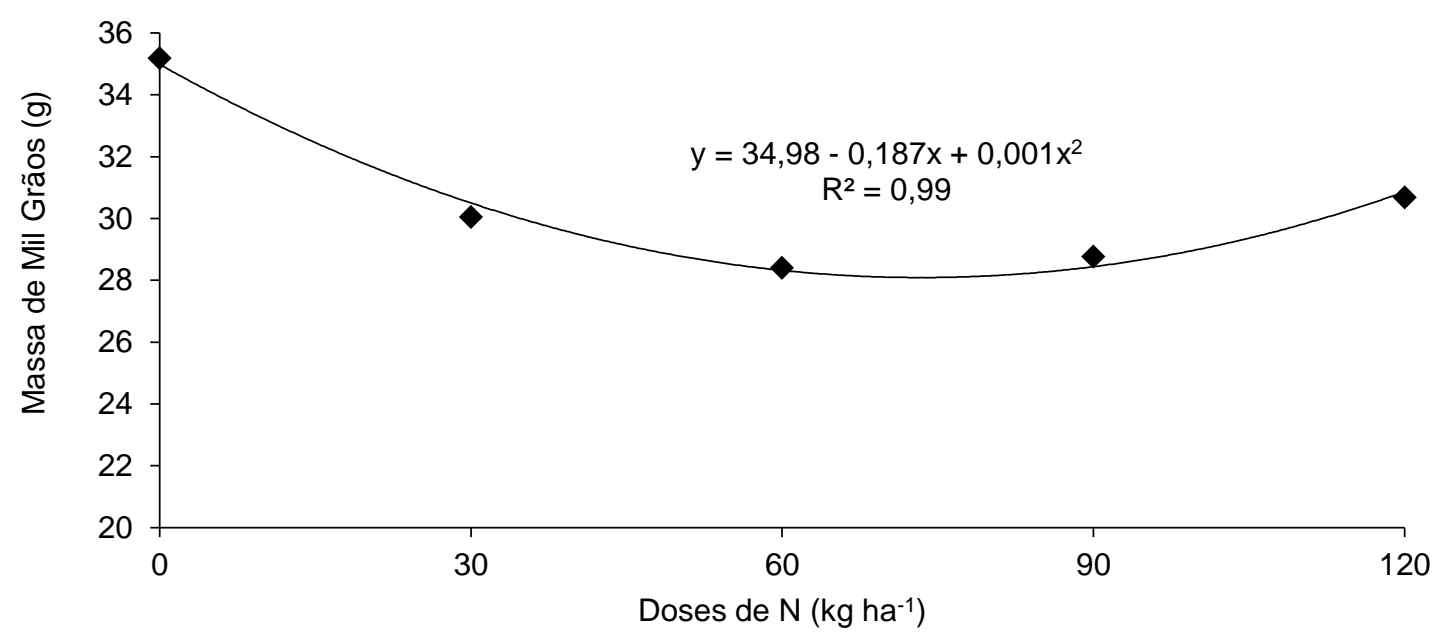

Figura 3. Variável massa de mil grãos em função das doses de nitrogênio aplicadas em trigo cultivado em Ouro Verde do Oeste - PR.

Para o peso do hectolitro $(\mathrm{PH})$, foram observadas valores inferiores a $78(\mathrm{~kg}$ $\left.100 \mathrm{~L}^{-1}\right)$. Isso pode ser explicado pela ocorrência diferencial de chuvas no final do ciclo da cultura.

Para a produtividade, o experimento conduzido não apresentou diferenças significativas, fato este que pode ter relação direta as condições climáticas adversas (altas precipitações pluviais) durante a condução, condições químicas do solo e, manejo do presente trabalho.

\section{DISCUSSÃO}

A ausência de efeito significativo para a varíavel altura de planta, pode estar relacionado a cultivar de trigo utilizada a CD 150, de porte baixo e resistência ao acamamento. Por outro lado, deve-se levar em consideração as condições do solo, em que o experimento foi conduzido por apresentar boa fertilidade como observado na análise química realizada, além das condições ambientais, com alto índice pluviométrico registrado, que pode acarretar maior crescimento vegetativo, e desfavorecer o efeito do $\mathrm{N}$. 
Em trabalho realizado por Teixeira Filho et al. (2010) em que avaliaram a aplicação de diferentes doses, com diferentes fontes e em diferentes épocas de aplicação, obtiveram resultados semelhantes a este trabalho quanto à altura de plantas em relação as dose aplicadas. Resultados contrários foram obtidos por Zagonel et al. (2002), trabalhando com doses de $N\left(0,45,90\right.$ e $\left.135 \mathrm{~kg} \mathrm{ha}^{-1}\right)$ em cobertura e diferentes densidades de plantas com e sem um regulador de crescimento, verificaram que com o aumento da dose de $\mathrm{N}$, ocorreu aumento da estatura das plantas, o que pode ser explicada pela competição por fatores essências de desenvolvimento como a luminosidade, permitindo assim que as plantas tenham alongamento dos entrenós.

Para a variável número de perfilho (NP), este resultado permite inferir que altas dosagens de $\mathrm{N}$, não são consideradas benéficas, podendo resultar em consumo de luxo, ou seja, a absorção de $\mathrm{N}$ não ocasionará incremento, pois a planta atingiu sua produtividade máxima. Isso implica em maiores gastos com fertilizantes nitrogenados neste caso, sem haver o devido retorno econômico, além de que dependendo do material genético e do momento da aplicação pode levar ao acamamento de plantas, ou para que isto não aconteça, torna-se necessário a aplicação de regulares de crescimento.

Afirmamos também que a aplicação de $\mathrm{N}$ em cobertura, não é capaz de aumentar o número de perfilhos, pois trata-se de uma característica genética da cultivar, do manejo populacional e das condições térmicas decorrentes durante seu desenvolvimento (PENCKOWSKI et al., 2009). Entretanto, a aplicação de $\mathrm{N}$ em cobertura durante este estádio inicial de perfilhamento (E2) permite que haja maior produção de fotoassimilados que serão armazenados nos perfilhos para a nutrição dos perfilhos férteis, pois nem todos perfilhos produzirão espigas, auxiliando assim o desenvolvimento das espigas e contribuindo para um maior desenvolvimento de espiga em relação ao seu tamanho e possivelmente no número de espiguetas por espiga e grãos por espiguetas.

Orso et al. (2014), relatam que o número de perfilho é determinado em função da população de plantas da área em geral, em que o número de perfilhos sofre alterações para compensar a falta ou o excesso de plantas. Almeida et al. (2002) 
observaram efeito positivo do $\mathrm{N}$ na emissão, desenvolvimento e sobrevivência de perfilhos.

Para Espindula et al. (2010), outro fator relevante pode estar associado a este fator denominado poder compensatório no qual o aumento de uma característica pode limitar a outra, ou seja, quanto maior o número de perfilhos maior também será a quantidade de folhas e, em consequência, a competição por fotoassimilados se acentua no interior das plantas.

É possível ressaltar ainda para a variavel tamanho da espiga, que o $\mathrm{N}$ por ser componente de proteínas e pigmentos fotossintéticos, quando suprido adequadamente pode incrementar o potencial fotossintético das folhas $\mathrm{e}$ isso também se relaciona diretamente com o maior crescimento das espigas de trigo (PICOLI JUNIOR, 2011).

O $\mathrm{N}$ desempenha diversas funções elevando compostos responsáveis pelo crescimento e desenvolvimento da cultura. Corassa et al. (2013), estudando o uso de adubação nitrogenada em associação com Azospirillum brasilense não obteveram respostas significativas para o componente comprimento de espiga. Teixeira Filho et al. (2007) obtiveram efeitos positivos até as doses de $120 \mathrm{~kg} \mathrm{ha}^{-1}$ para os caracteres rendimento, altura de plantas, comprimento de espigas, número de grãos por espiga.

No trabalho de Teixeira Filho et al. (2010), observaram que houve efeito significativo para número de espiguetas por espigas e número de grãos por espiga, quando se utilizou nitrogênio em cobertura, entretanto, em relação ao momento de aplicação e a doses de fertilizante foliar não houve efeito significativo para nenhuma das variáveis analisadas.

Portanto, pode-se afirmar que adequada adubação de $\mathrm{N}$ em cobertura ou um bom suprimento no solo, pode proporcionar bons resultados para estes parâmetros, como observado pela análise química do solo onde foi implantado este experimento. Esses resultados são semelhantes aos encontrados por Braz et al. (2006), em que avaliaram a cultura do trigo em sucessão a diferentes cultivos.

Para não contradizer a discussão acima, afirmamos que pelos resultados obtidos, um bom suprimento de $\mathrm{N}$ no solo é imprescindível para obter altas produtividades por meio da expressão de maior número de espiguetas, entretanto, 
pela aplicação de $\mathrm{N}$ em cobertura em diferentes dosagens poderá resultar sim em maior número de perfilho devido ao aumento de reservas para sua sobrevivência, e não devido ao $\mathrm{N}$ estimular maior diferenciação de perfilhos.

Assim, mesmo havendo maior número de perfilhos devido sua maior nutrição e, proporcionando em maior comprimento ou tamanho de espiga, nem sempre estará relacionado diretamente em maior produtividade, fato este observado pelo não efeito sobre a variável número de espiguetas, lembrando que o mais importante componente de produção de espécies graníferas é o número de grãos, onde não havendo efeito sobre está variável, dificilmente haverá efeito sobre a produtividade, mesmo havendo aumento na massa dos grãos.

Resultados semelhantes foram encontrados por Mendes et al. (2011) para a variável número de grãos por espiga, onde verificaram que doses crescentes de nitrogênio não influenciaram no número de grãos por espiga, apenas a testemunha apresentou diferença significativa (menor média) em relação aos demais tratamentos.

Em trabalho realizado por Mota et al. (2015), avaliando o uso de fontes estabilizadoras de nitrogênio através do uso de inibidores de urease, verificaram que para massa de mil grãos e o número de grãos/espiga foram influenciados significativamente pela fonte de $\mathrm{N}$ empregada. Da mesma forma Benett et al. (2011) avaliando a aplicação de $\mathrm{N}$ via foliar e em cobertura para a cultura do trigo no cerrado por um período de dois anos, obtiveram respostas positivas para as características produtivas para ambas as formas de aplicação.

Este resultado em relação a MMG, pode ser explicado possivelmente pela presença de um maior número de espigas, já que a maioria dos perfilhos contabilizados $(<95 \%)$ eram férteis, ou seja, apresentam espiga. Isso pode acarretar em uma possível competição por reservas nas plantas e por consequência um menor enchimento de grãos. Como não foi contabilizado a eficiência dos perfilhos, torna-se imprescindível novos trabalhos para poder afirmar tal hipótese. Entretanto, em trabalho realizado por Valério et al. (2008), observaram diminuição da MMG na espiga em genótipos de trigo com maior número de perfilhos.

Zagonel et al. (2002), verificaram que a adubação nitrogenada não influenciou a massa de mil grãos. Por sua vez, Coelho et al. (1998) verificaram aumento na 
massa de mil grãos até a aplicação de $37,2 \mathrm{~kg} \mathrm{ha}^{-1}$ de $\mathrm{N}$, em duas safras avaliadas, com diminuição nesse componente por meio de aplicação de doses superiores a esta mencionada.

Segundo Furlani et al. (2002), uma chuva sobre a lavoura madura reduz o $\mathrm{PH}$ e, consequentemente, afeta a qualidade de grãos. Avaliação esta que serve como parâmetro para a comercialização de grãos, uma vez que na prática, o valor recebido pelo produtor é menor quando o $\mathrm{PH}$ se apresenta abaixo de 78 (Tipo 1), não havendo diferença significativa entre os tratamentos.

Isso evidencia que a eficiência do $\mathrm{N}$ aplicado depende de fatores como cultivar, clima e manejo anterior a implantação. Entretanto, quando não houver efeitos diretos destas condições mencionadas, a adubação nitrogenada em cobertura na quantidade e fonte adequada, pode influenciar diretamente o fator produtividade e a qualidade do trigo, promovendo o máximo potencial de produtividade (MEGDA et al., 2009).

\section{CONCLUSÕES}

A aplicação do nitrogênio influencia positivamente o número de perfilhos e no tamanho da espiga das plantas de trigo até doses de aproximadamente $66 \mathrm{~kg} \mathrm{ha}^{-1}$ de $\mathrm{N}$, entretanto, estas variáveis não influenciaram a produtividade de grãos.

Doses acima de $30 \mathrm{~kg} \mathrm{ha}^{-1}$ de $\mathrm{N}$ em cobertura influenciaram negativamente a massa de mil grãos, e pode ter ocasionado o baixo PH observado, uma vez que o número de perfilhos que foi acrescido gera maior divisão dos fotoassimilados pelas plantas.

\section{REFERÊNCIAS}

ALMEIDA, M.L.; SANGOI, L.; TRENTIN, P.S; GÁLIO, J. Cultivares de trigo respondem diferentemente à qualidade da luz quanto à emissão de afilhos e acumulação de massa seca. Ciência Rural, Santa Maria, v. 32, n. 3, p. 377-383, 2002.

BENETT, C.G.S.; BUZETTI, S.; SILVA, K.S.; FILHO, M.C.M.T.; ANDREOTTI, M.; ARF, O. Aplicação foliar e em cobertura de nitrogênio na cultura do trigo no cerrado. Semana Ciências Agrárias, Londrina, v. 32, n. 3, p. 829-838, 2011. 
BRAZ, A.J.B.P.; SILVEIRA, P.M.; KLIEMANN, H.J.; ZIMMERMANN, F.J.P. Adubação nitrogenada em cobertura na cultura do trigo em sistema de plantio direto após diferentes culturas. Ciência e Agrotecnologia, v.30, p.193-198, 2006.

BRASIL. Ministério da Agricultura, Pecuária e Abastecimento. Regras para análise de sementes. Secretaria de Defesa Agropecuária. Brasília, DF: Mapa/ACS. p.395, 2009.

CBPTT. COMISSÃO BRASILEIRA DE PESQUISA DE TRIGO E TRITICALE. Informações técnicas para trigo e triticale: safra 2014. Londrina: Fundação Meridional, 2013. 235 p.

COELHO, M.A.O.; SOUZA, M.A.; SEDIYAMA, T.; RIBEIRO, A.C.; SEDIYAMA, C.S. Resposta da produtividade de grãos e outras características agronômicas do trigo Embrapa-22 irrigado ao nitrogênio em cobertura. Revista Brasileira de Ciência do Solo, v. 22, p.555-561, 1998.

CORASSA, G.M.; BERTOLLO, G.M.; GALLON, M.; BONA, S.D.; SANTI, A.L. Inoculação com Azospirillum brasilense associada à adubação nitrogenada em trigo na região Norte do Rio Grande do Sul. Enciclopédia Biosfera, Centro Científico Conhecer, Goiânia, v.9, n. 16, p. 1298, 2013.

COODETEC. Guia de produtos 2014. Região Sul. Variedades de Trigo. Disponível em:<http://www.coodetec.com.br/downloads/guia-de-produtos-2014-sul.pdf>. Acesso em:12 Ago 2015.

ESPINDULA, M.C.; ROCHA, V.S.; SOUZA, L.T.; SOUZA, M.A.; GROSSI, J.A.S. Efeitos de reguladores de crescimento na elongação do colmo de trigo. Acta Scientiarum Agronomy, Maringá, v. 32, n. 1, p. 109-116, 2010.

FERNANDES, M.S. Nutrição mineral de plantas. Viçosa, MG: Sociedade Brasileira de Ciência do Solo, 2006. 432 p.

FERREIRA, D.F. Sisvar Versão 5.4. Lavras: DEX/UFLA, 2011.

FRANCO, F.D.A.; EVANGELISTA, A. Reunião da Comissão Brasileira de Pesquisa de Trigo e Triticale. Informações técnicas para trigo e triticale safra 2018. Coodetec, Cascavel PR, 2018. 258p.

FURLANI, A.M.C.; GUERREIRO FILHO, O.; COELHO, R.M.; BETTI, J.A.; FREITAS, S.S. Recomendações da comissão técnica de trigo para 2002. 3.ed. Campinas: Instituto Agronômico, 2002. 92p. (Série tecnológica APTA. Boletim técnico IAC, 167).

INSTITUTO AMBIENTAL DO PARANÁ (IAPAR). Informações técnicas para trigo e triticale safra 2013. Edição única. Londrina. PR: Instituto Agronômico do Paraná (IAPAR, 2013).

LARGE, E. C. Growth stage in cereals: illustration of the Feekes scale. Plant Pathology, v. 3, p. 128-129, 1954. 
MEGDA, M.M.; BUZETTI, S.; ANDREOTTI, M.; TEIXEIRA FILHO, M.C.M.; VIEIRA, M.X. Resposta de cultivares de trigo ao nitrogênio em relação às fontes e épocas de aplicação sob plantio direto e irrigação por aspersão. Ciência e Agrotecnologia, v.33, p.1055-1060, 2009.

MENDES, M.C.; ROSÁRIO, J.G. do; FARIA, M.V.; ZOCCHE, J.C.; WALTER, A.L.B. Avaliação da eficiência agronômica de Azospirillum brasilense na cultura do trigo e os efeitos na qualidade de farinha. Revista Brasileira de Tecnologia Aplicada nas Ciências Agrárias, Guarapuava-PR, v. 4, n.3, p.95-110, 2011.

MOTA, M.R,; SANGOI, L.; SCHENATTO, D.E.; GIORDANI, W.; BONIATTI, C.M.; DAL'IGNA, L. Fontes estabilizadas de nitrogênio como alternativa para aumentar o rendimento de grãos e a eficiência de uso do nitrogênio pelo milho. Revista Brasileira Ciências do Solo. v. 39, p. 512-522, 2015.

ORSO, G.; VILLETTI, H.V.; KRENCHINSKI, F.H.; ALBRECHT, A.J.P.; ALBRECHT, L.P.; RODRIGUES, D.R.; MORAES, M.F. Comportamento da cultura do trigo sob efeito de fontes e doses de nitrogênio. Revista do Centro Universitário de Patos de Minas, v.5, p.44-52, 2014.

PENCKOWSKI, L.H.; ZAGONEL, J.; FERNANDES, E.C. Nitrogênio e redutor de crescimento em trigo de alta produtividade a produtividade. Acta Scientiarum Agronomy, Maringá, v. 31, n. 3, p. 473-479, 2009.

PICOLI JUNIOR, G. J. Adubação nitrogenada como estratégia para minimizar estresses ocasionados pela desfolha e fitotoxicidade foliar em milho. 2011. 88p. Dissertação (Mestrado Produção Vegetal) - Universidade do Estado de Santa Catarina, Lages, 2011.

RAIJ, B. van; ANDRADE, J.C.; CANTARELLA, H. \& QUAGGIO, J.A. Análise química para avaliação da fertilidade de solos tropicais. Campinas, Instituto Agronômico, 2001. 284p.

REIS JUNIOR, F.B.; MENDES, I. de C.; REIA, V.M.; CUNHA, M.H. da. Fixação Biológica de Nitrogênio: uma revolução na agricultura. In: FALEIRO, F. G.; ANDRADE, S. R. M. de.; REIS JUNIOR, F. B. dos. Biotecnologia: estado da arte e aplicações na agropecuária. 1 ed. Planaltina, DF: Embrapa Cerrados, p. 247-28, 2011.

SANTOS, H.G.; JACOMINE, P.K.T.; ANJOS, L.H.C. dos; OLIVEIRA, V.A. de; LUMBRERAS, J.F.; COELHO, M.R.; ALMEIDA, J.A. de; ARAÚJO FILHO, J.C. de; OLIVEIRA, J.B. de; CUNHA, T.J.F. Sistema Brasileiro de Classificação de Solos. $5^{\mathrm{a}}$ rev. e ed. Brasília - DF: Embrapa, 2018. 356p.

SILVA, P.R.F.; STRIEDER, M.L.; COSER, R.P.S.; RAMBO, L.; SANGOI, L.; ARGENTA, G.; FORSTHOFER, E.L.; SILVA, A.A. da. Grain yield and kernel protein content increases of maize hybrids with late nitrogen side-dresses. Scientia Agrícola, Piracicaba, v.62, n.5, p.487-492, 2005. 
TEIXEIRA FILHO, M.C.M.; BUZETTI, S.; ALVAREZ, R.C.F.; FREITAS, J.G.; ARF, O.; SÁ, M.E. Resposta de cultivares de trigo irrigado por aspersão ao nitrogênio em cobertura na Região do Cerrado. Acta Scientiarum Agronomy, Maringá, v. 29, n. 3, p. 421-425, 2007.

TEIXEIRA FILHO, M.C.M.; BUZETTI, S.; ANDREOTTI, M.; ARF, O.; BENETT, C.G.S. Doses, fontes e épocas de aplicação de nitrogênio em trigo irrigado em plantio direto. Pesquisa Agropecuária Brasileira, Brasília, DF, v. 45, n. 8, p. 797804, 2010.

TRINDADE, M. G.; STONE, L.F.; HEINEMANN, A.B.; CÁNOVAS, A.D.; MOREIRA, J.A.A. Nitrogênio e água como fatores de produtividade do trigo no Cerrado. Revista Brasileira de Engenharia Agrícola e Ambiental, Campina Grande, v. 10, n. 1, p. 24-29, 2006.

VALÉRIO, I.P.; CARVALHO, F.I.F.; OLIVEIRA, A.C.; MACHADO, A.A.; BENIN, G.; SCHEEREN, P.L.; SOUZA, V.Q.; HARTWIG, I. Desenvolvimento de afilhos e componentes do rendimento em genótipos de trigo sob diferentes densidades de semeadura. Pesquisa Agropecuária Brasileira, v.43, n.3, p.319-326, 2008.

ZAGONEL, J.; VENANCIO, W.S.; KUNZ, R.P.; TANAMATI, H. Doses de nitrogênio e densidade de plantas com e sem um regulador de crescimento afetando o trigo, cultivar OR-1. Ciência Rural, Santa Maria, v. 32, n. 1, p. 25-29, 2002. 